\title{
CHILD HEALTH AND MATERNAL WORK ACTIVITY: THE ROLE OF UNOBSERVED HETEROGENEITY
}

\author{
David Zimmer \\ Western Kentucky University
}

\section{INTRODUCTION}

A mother's work activity is potentially affected by the health of her child. On one hand, a child in poor health might require costly health care, which could necessitate a mother's employment. On the other hand, a child's health condition might require time-intensive parental care, which could preclude a mother's labor market activity. This issue is increasingly important because, as Salkever [1982] notes, as female labor force participation rates continue to increase, time spent at home with children might be reduced. Powers [2003] states that an increasing number of households contain at least one child with a health problem, and mothers in those households might encounter obstacles to employment. She notes that policies that pay compensation to families of disabled children award benefits based, in part, on the belief that child health problems impede parental work. Disability compensation to children is viewed as a way to alleviate a family's financial difficulties associated with reduced work. Therefore, quantifying the link between child health and maternal work is necessary to formulate disability compensation policies. This paper attempts to determine whether a mother's labor market behavior is affected by the presence of an unhealthy child.

This question takes on greater importance after the 1996 welfare reforms. In 1996, Congress passed the Personal Responsibility and Work Opportunity Reconciliation Act, which reversed the entitlement to public assistance and imposed new and stricter work requirements for those receiving aid. In the post welfare reform era, a vital policy question is whether mothers with unhealthy children have different labor market participation than mothers with healthy children. Most existing studies on this topic have found that the presence of an unhealthy or disabled child has a negative effect on a mother's labor market activity. However, estimating the causal relationship is complicated because unobserved heterogeneity that affects a child's health might also affect the mother's labor market attachment. This has rarely been addressed in the existing literature, which is discussed in the next section.

Yet there is reason to suspect that a child's health and maternal work activity are both affected by unobserved heterogeneity. Mothers with healthy children might differ from mothers with unhealthy children in ways that are not observed in household surveys. Powers [2003, 541] explains that "There is also the possibility, not confronted in this or previous work, that unobserved maternal ability and children's

David Zimmer: Department of Economics, Western Kentucky University,1906 College Heights Boulevard, Bowling Green, Kentucky 42101. E-mail: dmzimmer@gmail.com.

Eastern Economic Journal, Vol. 33, No. 1, Winter 2007 
health are correlated." It might be those unobserved factors that affect maternal work patterns-not necessarily the presence per se of healthy or unhealthy children. Empirical evidence supporting this hypothesis would suggest that the lower labor supply of mothers of unhealthy children might reflect other underlying and unobserved factors rather than the health of their children. This paper uses a recently conducted household survey of the U.S. population to estimate the effect of child health on mothers' labor supply. The main contribution of this study is that unique variables measuring access to care are employed as instruments in a model that accounts for bias caused by unobserved heterogeneity. Results of instrumental variable estimation indicate that the presence of a child with health problems does not appear to directly affect a mother's labor market activity.

The rest of the paper is organized as follows. The second section reviews the relevant literature. The third section presents a theoretical model of maternal labor supply and outlines an estimation strategy. The fourth section discusses the Medical Expenditure Panel Survey data. The fifth section conducts overidentifying tests of instrument validity. The sixth section discusses the most relevant paper to this study [Corman, Noonan, and Reichman, 2005] and attempts to replicate their results. The seventh section presents results of estimation, and the final section concludes.

\section{LITERATURE REVIEW}

Two of the earliest papers on the topic reveal that child health might adversely affect maternal employment. Salkever [1982] examines a sample of wives and single mothers from the 1972 National Health Interview Survey. His measure of child health is a dichotomous indicator of whether each mother has a child with an activity or mobility limitation caused by a chronic condition. He finds that in white two-parent families, the presence of a child with a limitation reduces the probability that the mother was consistently working during the previous year. Breslau, Salkever, and Staruch [1982] conduct a survey of Cleveland families that focuses on families of children with cystic fibrosis, cerebral palsy, myelodysplasia, or multiple physical handicaps. They find that mothers of children with these conditions have lower probabilities of labor force participation, and the effect is more pronounced for blacks and lower income couples.

Several recent papers have come to similar conclusions using updated data sources and different definitions of child health. Roberts [1999] extracts a sample from the 1987 National Medical Expenditure Survey to estimate the effects of mental illness. She finds that labor force participation is reduced when any family member has both a physical and mental illness. Lukemeyer, Meyers, and Smeeding [2000] focus on poor families from wave II of the California AFDC Household Survey. They consider a child to be in poor health if he or she receives SSI compensation or has a chronic health problem or disability that limits activities. The main findings are that child health problems lead to reductions in employment and hours worked. Porterfield [2002] and Powers [2003] both use Survey of Income and Program Participation (SIPP) data from the early 1990s, and both find that disabled children negatively affect maternal labor force attachment. 
Four studies investigate the effects of child health on female heads of households. Blank [1989] uses data from the National Medical Care Utilization and Expenditure Survey, and Wolfe and Hill [1995] use SIPP data from the early 1980s. Both of these studies find that child health problems negatively affect employment activity of female heads, although Blank's main focus is overall family health. Two papers on female heads produce mixed results. Salkever [1990] studies a sample of healthy female heads from the 1976 Survey of Income and Education. He finds that labor force participation is lower in the presence of a child with limitations in play or schoolwork, but he finds no effect of such limitations on hours worked. Similarly, Kimmel [1997] uses the 1987 wave of the SIPP to examine the effects of chronic physical, mental, or emotional conditions that limit the ability to run, walk, or play. Kimmel finds no effect on maternal labor force participation.

Two papers have made explicit attempts to account for the presence of unobserved heterogeneity. Norberg [1998] uses the 1994 wave of the National Longitudinal Survey of Youth to study the effect of child health problems on young mothers' work behavior. She focuses specifically on child health complications that are present at birth, which reduces the likelihood that child health and maternal work are both affected by a common source of unobserved heterogeneity. She finds that health complications at birth reduce the probability of mothers returning to the labor force.

The most recent paper on this topic is Corman, Noonan, and Reichman [2005]. Because of its importance to this study, it is discussed in more detail in the section on Comparison with CNR; their main finding is that the presence of an unhealthy child reduces the probability of maternal employment and paternal hours worked. They limit their study to mothers of children between ages 0 and 2. Similar to Norberg [1998], they focus on child health problems that are present at birth or early in child development, thus reducing the probability that their results are contaminated by unobserved heterogeneity.

Aside from Salkever's [1990] model of hours worked and Kimmel's [1997] model of labor force participation, most existing studies find that the presence of unhealthy or disabled children reduces maternal work activity. It is not clear why their results differ from other studies. Possible explanations are that Salkever focuses only on healthy women, who are more likely to remain employed in the event of child health complications. Kimmel's finding might be due to child health being defined as a chronic disabling condition. Perhaps after caring for a disabled child for an extended period of time, mothers are able to adapt and return to employment. However, despite the few studies using child health measures that can be justified as predetermined, the majority of these studies do not adequately control for unobserved heterogeneity that simultaneously affects child health and maternal work. Only two of the above mentioned papers have attempted to address the presence of unobserved heterogeneity: Norberg [1998] uses fixed effects in a longitudinal sample, and Corman, Noonan, and Reichman [2005] employ instrumental variables methods. Both papers focus exclusively on young mothers and children with health problems present since birth. Aside from these two studies, virtually every other paper estimates employment and hours worked with a single equation linear or limited dependent variable model. The purpose of this paper is to estimate the effects of child health on a wider sample of 
women while controlling for observed and unobserved confounding factors that might simultaneously influence child health and maternal work activity.

\section{MATERNAL EMPLOYMENT AND CHILD HEALTH}

This section outlines theoretical origins of a model of child health and maternal employment and discusses an estimation strategy.

\section{Theoretical Model of Maternal Work}

A mother's equilibrium hours of work are determined by equating her market wage to her shadow price of nonworking activities. She works only if her market wage is greater than her shadow price of working zero hours. Following Heckman [1974] and Salkever [1982], the shadow price of nonworking time is a function of her personal and demographic characteristics, including the health of her children. ${ }^{1}$ In order to estimate the effect of child health on work behavior, all relevant information, aside from random variation, that affects maternal labor supply must be observable, which implies that child health is a predetermined state. However, if mothers with healthy children and mothers with unhealthy children differ in ways that are not observed to researchers, and if those differences are correlated with child health, then estimates of the effect of child health are biased. Ignoring unobserved heterogeneity might lead to incorrect inferences about the effect of child health on maternal work activity. For example, if mothers possess unobserved personal or socioeconomic characteristics that adversely affect the health of their children while at the same time discouraging labor participation, then estimation procedures that do not account for these unobserved confounding factors lead one to incorrectly infer that child health directly affects maternal work. In order to uncover accurate measures of the effect of child health, bias caused by omitted variables must be addressed empirically.

\section{Estimation Strategy}

This model uses two different measures of maternal employment activity. First, a dichotomous variable indicates whether the mother is employed (EMPLOYED). Second, the labor supply decision is reflected in her number of hours per week (HOURS). For the EMPLOYED model, a linear probability model (LPM) is used which offers two advantages over a probit model. First, the LPM formulation permits use of instrumental variables (IV) analysis to account for potential endogeneity of child health. Second, while Corman, Noonan, and Reichman [2005] attempt to control for endogeneity and test their instruments by way of a bivariate probit model, the LPM estimated by instrumental variables methods permits a formal test of instrument validity in the presence of overidentifying restrictions. ${ }^{2}$

More than 34 percent of mothers in the sample report zero hours worked per week, which necessitates use of a Tobit model in the HOURS model. To account for unobserved heterogeneity, a two-step procedure is used. In the first step, a probit model estimates whether a mother has an unhealthy child, and fitted probabilities of child health are generated. In the second step, the fitted probabilities from the first step are 
used in place of the child health variable, and a Tobit model for hours is estimated. In order to account for the fact that child health is estimated in a first stage, standard errors are calculated using the bootstrap procedure developed by Efron [1979]. ${ }^{3}$

\section{DATA}

Data are from the 1996, 2000, and 2001 waves of the Medical Expenditure Panel Survey (MEPS) conducted by the Agency for Healthcare Research and Quality, a unit of the Department of Health and Human Services. MEPS is a large household survey of respondents drawn from the National Health Interview Survey and is designed to be nationally representative of the U.S. noninstitutionalized population. The survey consists of a series of five interviews over a two-and-a-half year period and records socioeconomic and health related information for each individual. While the multiple interview format of MEPS permits some limited longitudinal applications, child health variables relevant to this study are recorded only once a year. Therefore, the years are stacked and treated as a cross section sample. However, in light of modeling flexibilities offered by longitudinal analysis, comparison of MEPS to a separate longitudinal study is presented in the section on Results of Estimation. This longitudinal sample consists of 2,237 mothers drawn from the 1979 National Longitudinal Survey of Youth (NLSY) and is discussed in greater detail in the subsection NLSY Comparison.

MEPS provides numerous advantages for studying child health and maternal employment. It contains detailed information about mothers' work activity, marital status, and socioeconomic characteristics, and it includes several detailed measures of the health status of children. The sample consists of all women between ages 19 and 64 , married or not, who have at least one child younger than 16 years of age. Sample averages are reported in Table 1 . More than 70 percent of the mothers are married (MARRIED), approximately 15 percent are divorced, widowed, or separated from their husbands (DIVSEP), and the remainder have never been married.

\section{Measures of Child Health}

MEPS records self-reported physical and mental health based on a five-point scale: excellent, very good, good, fair, and poor. The variable FAIRPOOR is a dichotomous variable indicating whether the family has any child in fair or poor physical health. The variable MFAIRPOOR is a similar variable indicating the presence of any child in fair or poor mental health. ${ }^{4}$ Approximately 6 percent of mothers have a child in fair or poor physical health, and approximately 3 percent have a child in fair or poor mental health. In addition to these two measures of health, LESSHEALTHY is a dichotomous variable indicating the presence of any child who is less healthy than other children of similar age. Approximately 18 percent of mothers have a child who is less healthy than other children.

One potential weakness of these measures of child health is that they are selfreported and therefore subject to differences in self perception across individuals. Although virtually all previous studies have relied on some form of self-reported child health, a less subjective measure might be preferred. Unfortunately, most large household surveys such as MEPS collect information directly from respondents and rarely 
conduct cross validation checks. In an attempt to include a measure of child health that is less sensitive to respondents' self perception, a fourth variable, ASSISTANCE, is used which indicates whether the child requires personal or mechanical assistance for "Activities of Daily Life" or "Instrumental Activities of Daily Life" as originally defined by the National Health Interview Survey. Approximately 1 percent of mothers have a child who needs such assistance. Although this variable is self-reported, it is less subjective than other measures of self-reported health, because whether a child requires personal or mechanical assistance for routine functions is more transparent than a person's own assessment of his or her health.

TABLE 1

Sample Means of Mothers between age 18 and $64(\mathrm{~N}=8773)$

Medical Expenditure Panel Survey

Years 1996, 2000, 2001

\begin{tabular}{|c|c|c|}
\hline Variable & Definition & Mean \\
\hline \multicolumn{3}{|l|}{ Socioeconomic } \\
\hline AGE & Age & 35.33 \\
\hline EDUC & years of education & 12.36 \\
\hline FAMSIZE & family size & 4.18 \\
\hline BLACK & 1 if black & 0.16 \\
\hline HISPANIC & 1 if Hispanic & 0.28 \\
\hline DIVSEP & 1 if divorced, widowed, or separated & 0.15 \\
\hline MARRIED & 1 if married & 0.71 \\
\hline NOREAST & 1 if northeast & 0.17 \\
\hline MIDWEST & 1 if Midwest & 0.20 \\
\hline SOUTH & $\begin{array}{l}1 \text { if south } \\
\text { (Excluded regional category is west) }\end{array}$ & 0.37 \\
\hline MSA & 1 if MSA & 0.80 \\
\hline UNEMP & Unemployment rate is region and year of observation & 4.60 \\
\hline GOOD & 1 if good health & 0.27 \\
\hline FAIR & 1 if fair health & 0.10 \\
\hline POOR & $\begin{array}{l}1 \text { if poor health } \\
\text { (Excluded health category is very good or excellent health) }\end{array}$ & 0.02 \\
\hline KID0-5 & 1 if child between 0 and 5 & 0.47 \\
\hline KID6-11 & 1 if child between 6 and 11 & 0.55 \\
\hline KID12-15 & 1 if child between 12 and 15 & 0.39 \\
\hline \multicolumn{3}{|l|}{ Employment } \\
\hline EMPLOYED & 1 if employed & 0.74 \\
\hline HOURS & average hours worked per week & 23.62 \\
\hline \multicolumn{3}{|l|}{ Child Health } \\
\hline FAIRPOOR & 1 if child in fair or poor health & 0.06 \\
\hline MFAIRPOOR & 1 if child in fair or poor mental health & 0.03 \\
\hline LESSHEALHY & 1 if child who is less healthy than other kids & 0.18 \\
\hline ASSISTANCE & 1 if needs mechanical or personal assistance due to health condition & 0.01 \\
\hline \multicolumn{3}{|l|}{ Access to Care } \\
\hline PHONE & 1 if very difficult or somewhat difficult to contact provider by phone & 0.20 \\
\hline APPDIFF & 1 if very difficult or somewhat difficult to schedule appointment & 0.20 \\
\hline OBTAIN & 1 if any difficulty in family obtaining health & 0.14 \\
\hline
\end{tabular}




\section{Instruments}

Appropriate instrumental variables should be correlated with child health but uncorrelated with mothers' labor supply after controlling for covariates. In the only other study that attempts an instrumental variables approach, Corman, Noonan, and Reichman [2005] use two instruments: the number of adoption agencies per 10,000 women in the city in which the child was born and whether the hospital in which the child was delivered had a Level III neonatal intensive care unit. They mention that in previous investigations, their instruments were found to be theoretically valid. In particular, they find that their instruments are nontrivial predictors of child health. This is an important consideration since, as Nelson and Startz [1990] illustrate in a Monte Carlo experiment, IV estimates using weak instruments are potentially more biased than OLS estimates. This paper uses a different set of instruments than those employed by Corman, Noonan, and Reichman and formally tests the validity of the instruments. Results show that using a different set of instruments and a wider sample of women produces results that differ from conclusions of previous research.

MEPS data include measures of the relative ease with which individuals can obtain health care. Access to care might be an important determinant of child health, especially because young children typically require more frequent medical attention than adults. At the same time, access to care as measured in this paper is unlikely to be related to maternal work behavior. Although employers might provide mothers with insurance, which can increase choices of available care, access to care variables used in this paper measure the degree of difficulty a mother has contacting and receiving care from her usual source of care. Consequently, a mother without a usual source of care is less likely to report having such difficulties due to how access to care is measured in this survey. This reduces the probability that a mother will report difficulties in access to care because of her employment status. Therefore, identification relies on the hypothesis that access to care significantly affects child health but not mothers' labor supply, after controlling for other factors. Formal tests presented below support that hypothesis. This paper employs three instrumental variables that measure access to care: (1) whether it is "very difficult" or "somewhat difficult" for the family to contact its usual source of care by telephone (PHONE); (2) whether it is "very difficult" or "somewhat difficult" for the family to schedule an appointment with its usual source of care (APPDIFF); and (3) whether anyone in the family has difficulty obtaining care (OBTAIN). Respective sample proportions for these variables are $0.20,0.20$, and 0.14 . The presence of overidentifying restrictions permits formal tests of the validity of the instruments, which are discussed below.

\section{VALIDITY OF INSTRUMENTS}

Since reliability of the models depends heavily on the validity of the instruments, formal tests of instrument validity are presented before discussion of the results of estimation. For instruments to be valid they must be significant predictors of child health, and they must be uncorrelated with maternal work activity after controlling for other factors. As an initial check to determine whether the three instruments are 
correlated with maternal work patterns, the following table reports sample averages of employment variables across different values of the instruments.

\begin{tabular}{lcc} 
Instrument & Instrument = 1 & Instrument $=\mathbf{0}$ \\
\hline APPDIFF & \multicolumn{2}{c}{ Sample Mean of EMPLOYED } \\
PHONE & 0.76 & 0.74 \\
OBTAIN & 0.74 & 0.75 \\
\multicolumn{2}{c}{0.74} \\
APPDIFF & 0.74 & \multicolumn{2}{c}{23.5} \\
PHONE & \multicolumn{2}{c}{ Sample Mean of HOURS } \\
OBTAIN & 24.2 & 23.7 \\
\hline
\end{tabular}

Sample averages of the two employment variables do not appear to differ systematically with respect to different values of the instruments. This is suggestive evidence that the access to care variables are not correlated with maternal employment, even without conditioning on covariates; overidentifying tests presented below confirm that these are suitable instruments.

To determine whether the instruments significantly predict child health, first stage regressions of child health on all covariates are estimated with and without the instruments included. From these first stage regressions, F-tests are calculated in which the null hypothesis is that the three instruments together do not significantly affect child health. P-values, shown in the first and third columns of Table 2, lead to rejection of the null hypothesis at the 5 percent level for three of the four measures of child health, and at the 10 percent level for the remaining measure. Evidently, the relative ease with which a family is able to access its usual source of care has a significant effect on child health.

TABLE 2

Tests of Instrument Validity

\begin{tabular}{lcccc}
\hline & \multicolumn{2}{c}{ EMPLOYED } & HOURS \\
\hline Model & $\begin{array}{c}\text { First stage } \\
\text { F-stat } \\
\text { P-value }\end{array}$ & $\begin{array}{c}\text { Second stage } \\
\text { Hansen stat } \\
\text { P-value }\end{array}$ & $\begin{array}{c}\text { First stage } \\
\text { F-stat } \\
\text { P-value }\end{array}$ & $\begin{array}{c}\text { Second stage } \\
\text { Hansen stat } \\
\text { P-value }\end{array}$ \\
\hline LESSHEALTHY & $0.001^{* *}$ & 0.185 & $0.000^{* *}$ & 0.228 \\
ASSISTANCE & $0.056^{*}$ & 0.923 & $0.056^{*}$ & 0.262 \\
FAIRPOOR & $0.014^{* *}$ & 0.526 & $0.014^{* *}$ & 0.541 \\
MFAIRPOOR & $0.001^{* *}$ & 0.292 & $0.001^{* *}$ & 0.298 \\
\hline$*$
\end{tabular}

* significant at 10 percent level

** significant at 5 percent level

Note: Columns (1) and (3) show P-values of F-tests in which the null hypothesis is that the three instruments together do not significantly affect child health. Columns (2) and (4) show p-values of Hansen statistics in which the null hypothesis is that the three instruments are uncorrelated with the error in the mother's work equation.

To determine whether the instruments are uncorrelated with maternal work activity after controlling for covariates, Hansen [1982] chi-square statistics of overidentifying restrictions are calculated. ${ }^{5}$ The null hypothesis is that the instruments 
are not correlated with the error term in the work equation, which suggests that the instruments are valid exclusion restrictions. The associated P-values are presented in columns two and four of Table 2. They do not support rejection of this hypothesis for any of the measures of child health in either the EMPLOYED equation or the HOURS model. The lack of significance of the Hansen statistics is evidence of the validity of the instruments. The interpretation is that the three instruments are not correlated with maternal work behavior after conditioning on observed covariates.

One potential weakness of the instruments is that they are self-reported measures of how mothers perceive their access to care. Although the tests summarized in Table 2 show that the three instruments are unrelated to maternal employment and significantly related to child health, the fact that these are self-reported variables raises questions about their relation to child health. Does access to care affect child health (as posited above) or does child health affect access to care? As an informal check, first stage probits were estimated with and without the access to care variables, and a Hausman test was conducted on the remaining coefficients. This test revealed that other coefficients in the first stage probits did not differ systematically whether the access to care variables were included or excluded. This is suggestive evidence that the access to care variables are suitable instruments, but as a more convincing robustness exercise, maternal employment models are re-estimated using panel data from the 1979 National Longitudinal Survey of Youth (NLSY). Although NLSY is inferior to MEPS for the present application, its panel structure allows a different method by which to control for unobserved heterogeneity that simultaneously affects child health and maternal employment behavior. These results, discussed in subsection NLSY Comparison of the next to last section, are largely consistent with instrument variable results from MEPS and, thus lend support to the choice of access to care variables as instruments.

\section{COMPARISON WITH CNR}

For purposes of comparison with previous research, models are first estimated that mimic the methodology of Corman, Noonan, and Reichman [2005], hereafter referred to as CNR. The main purpose of this section is to determine whether child health and maternal work are subject to common unobserved heterogeneity. Because there is no formal test of unobserved heterogeneity for the tobit model, this section does not attempt to replicate results for the HOURS equation. Instead, that analysis is presented and discussed in the Results of Estimation section. CNR estimate a bivariate probit in which the outcome variables are dichotomous indicators of whether the mother is currently working and whether the child is in poor health. The child health variable is included in the set of explanatory variables in the mother's employment equation. Using MEPS data, results shown in Table 3 reveal that the three instruments are positively associated with less healthy children, although APPDIFF appears to be estimated with slightly less precision. ${ }^{6}$ Results of the child health equation reveal that educated and married mothers have children with fewer health problems, but maternal age and regional unemployment appear to be positively correlated with child health complications. 
TABLE 3

Bivariate Probit of Maternal Employment and Child Health

For Mothers with a Child Between Ages 0 and 15

\begin{tabular}{|c|c|c|c|c|c|c|c|c|}
\hline & \multicolumn{2}{|c|}{ LESSHEALTHY } & \multicolumn{2}{|c|}{ ASSISTANCE } & \multicolumn{2}{|c|}{ KFAIRPOOR } & \multicolumn{2}{|c|}{ KMFAIRPOOR } \\
\hline & Coeff. & St. Err. & Coeff. & St. Err. & Coeff. & St. Err. & Coeff. & St. Err. \\
\hline & \multicolumn{8}{|c|}{ Probit for Employed = 1} \\
\hline Child health measure & 0.732 & 0.485 & $1.738 * *$ & 0.254 & 0.493 & 0.413 & -0.110 & 0.660 \\
\hline KID0-5 & $-0.321 * *$ & 0.052 & $-0.337 * *$ & 0.041 & $-0.352^{* *}$ & 0.042 & $-0.354 * *$ & 0.042 \\
\hline KID6-11 & 0.001 & 0.034 & -0.001 & 0.035 & -0.007 & 0.036 & -0.005 & 0.036 \\
\hline KID12-15 & $0.104 * *$ & 0.041 & $0.102^{* *}$ & 0.040 & $0.104^{* *}$ & 0.042 & $0.111^{* *}$ & 0.043 \\
\hline FAMSIZE & $-0.095^{* *}$ & 0.014 & $-0.102^{* *}$ & 0.012 & $-0.103^{* *}$ & 0.012 & $-0.104^{* *}$ & 0.012 \\
\hline AGE & $0.044 * *$ & 0.022 & $0.060 * *$ & 0.015 & $0.061^{* *}$ & 0.016 & $0.064 * *$ & 0.016 \\
\hline AGE2 & $-0.001^{* *}$ & 0.000 & $-0.001^{* *}$ & 0.000 & $-0.001^{* *}$ & 0.000 & $-0.001^{* *}$ & 0.000 \\
\hline EDUC & $0.068 * *$ & 0.005 & $0.063^{* *}$ & 0.005 & $0.068^{* *}$ & 0.006 & $0.065^{* *}$ & 0.006 \\
\hline NOREAST & -0.062 & 0.055 & $-0.102^{* *}$ & 0.051 & $-0.092^{*}$ & 0.052 & -0.085 & 0.052 \\
\hline MIDWEST & $0.111^{*}$ & 0.062 & $0.106^{*}$ & 0.059 & $0.118^{*}$ & 0.061 & $0.136^{* *}$ & 0.060 \\
\hline SOUTH & $0.090 * *$ & 0.040 & 0.057 & 0.040 & $0.072^{*}$ & 0.040 & $0.074^{*}$ & 0.040 \\
\hline MSA & 0.028 & 0.039 & 0.016 & 0.039 & 0.028 & 0.040 & 0.022 & 0.040 \\
\hline UNEMP & $-0.070 * *$ & 0.028 & $-0.063^{* *}$ & 0.027 & $-0.067^{* *}$ & 0.029 & $-0.054^{*}$ & 0.028 \\
\hline BLACK & $0.157 * *$ & 0.053 & $0.182^{* *}$ & 0.048 & $0.172^{* *}$ & 0.049 & $0.177^{* *}$ & 0.049 \\
\hline HISPANIC & $-0.120 * *$ & 0.039 & $-0.128 * *$ & 0.039 & $-0.135^{* *}$ & 0.039 & $-0.127 * *$ & 0.039 \\
\hline MARRIED & -0.041 & 0.058 & -0.070 & 0.050 & $-0.064^{* *}$ & 0.052 & -0.081 & 0.055 \\
\hline DIVSEP & $0.232^{* *}$ & 0.061 & $0.209 * *$ & 0.062 & $0.223^{* *}$ & 0.063 & $0.225^{* *}$ & 0.064 \\
\hline GOOD & $-0.066^{* *}$ & 0.033 & $-0.073^{* *}$ & 0.034 & $-0.074^{* *}$ & 0.035 & $-0.072^{* *}$ & 0.036 \\
\hline FAIR & $-0.370 * *$ & 0.055 & $-0.400 * *$ & 0.048 & $-0.395^{* *}$ & 0.051 & $-0.393^{* *}$ & 0.051 \\
\hline POOR & $-0.876^{* *}$ & 0.116 & $-0.937 * *$ & 0.092 & $-0.937^{* *}$ & 0.095 & $-0.939 * *$ & 0.095 \\
\hline \multirow[t]{2}{*}{ INTERCEPT } & -0.157 & 0.313 & -0.134 & 0.302 & -0.219 & 0.306 & -0.247 & 0.313 \\
\hline & \multicolumn{8}{|c|}{ Probit for Child Health Measure $=1$} \\
\hline APPDIFF & 0.057 & 0.041 & 0.074 & 0.089 & 0.028 & 0.060 & 0.078 & 0.070 \\
\hline PHONE & $0.125^{* *}$ & 0.044 & -0.078 & 0.092 & 0.086 & 0.058 & $0.179 * *$ & 0.068 \\
\hline OBTAIN & $0.161^{* *}$ & 0.043 & $0.255^{* *}$ & 0.084 & $0.295^{* *}$ & 0.056 & $0.297 * *$ & 0.068 \\
\hline AGE & $0.067 * *$ & 0.016 & 0.038 & 0.033 & $0.041^{*}$ & 0.022 & $0.111^{* *}$ & 0.028 \\
\hline AGE2 & $-0.001 * *$ & 0.000 & 0.000 & 0.000 & $-0.001^{* *}$ & 0.000 & $-0.001^{* *}$ & 0.000 \\
\hline EDUC & $-0.031 * *$ & 0.006 & -0.008 & 0.012 & $-0.045^{* *}$ & 0.007 & $-0.051^{* *}$ & 0.009 \\
\hline NOREAST & -0.068 & 0.056 & $0.219 *$ & 0.116 & 0.103 & 0.077 & $0.164^{*}$ & 0.092 \\
\hline MIDWEST & 0.073 & 0.061 & $0.280 * *$ & 0.134 & $0.240 * *$ & 0.087 & $0.181^{*}$ & 0.105 \\
\hline SOUTH & $-0.087 * *$ & 0.042 & 0.133 & 0.095 & -0.002 & 0.058 & 0.068 & 0.071 \\
\hline MSA & -0.041 & 0.041 & 0.008 & 0.092 & $-0.116^{* *}$ & 0.056 & -0.029 & 0.070 \\
\hline UNEMP & $0.081 * *$ & 0.029 & $0.130 * *$ & 0.062 & $0.196^{* *}$ & 0.040 & $0.141^{* *}$ & 0.048 \\
\hline BLACK & 0.050 & 0.048 & -0.146 & 0.115 & 0.097 & 0.066 & -0.055 & 0.085 \\
\hline HISPANIC & 0.007 & 0.042 & 0.073 & 0.088 & $0.150 * *$ & 0.056 & -0.024 & 0.070 \\
\hline MARRIED & $-0.137^{* *}$ & 0.051 & -0.048 & 0.118 & $-0.172 * *$ & 0.067 & $-0.391 * *$ & 0.082 \\
\hline DIVSEP & -0.093 & 0.061 & -0.022 & 0.137 & 0.011 & 0.079 & $-0.217 * *$ & 0.095 \\
\hline INTERCEPT & $-1.944 * *$ & 0.317 & $-3.743 * *$ & 0.695 & $-2.509 * *$ & 0.434 & $-4.124 * *$ & 0.570 \\
\hline RHO & -0.512 & 0.291 & -0.822 & 0.114 & -0.270 & 0.205 & -0.017 & 0.296 \\
\hline LR Test & \multicolumn{2}{|c|}{$2.89 *$} & \multicolumn{2}{|c|}{$4.84^{* *}$} & \multicolumn{2}{|c|}{1.67} & \multicolumn{2}{|c|}{0.003} \\
\hline
\end{tabular}

* significant at 10 percent level ** significant at 5 percent level

CNR's model [2005] produces a negative but statistically insignificant coefficient of the child health variable using this specification. Following a similar estimation procedure, results in Table 3 indicate that child health is insignificant except for the case in which health is measured by the child's need for assistance in physical activity. In addition, CNR find no correlation between the probit error terms, which they 
interpret as evidence that child health is predetermined in the maternal work equation. Accordingly, they choose to report results which treat child health as predetermined, and results from those models show that child health has a negative and significant effect on maternal labor force attachment. By contrast, estimates in Table 3 reveal significant negative error correlations in two of the four models.

TABLE 4

Bivariate Probit of Maternal Employment and Child Health For Mothers with a Child Between Ages 0 and 2

\begin{tabular}{|c|c|c|c|c|c|c|c|c|}
\hline & \multicolumn{2}{|c|}{ LESSHEALTHY } & \multicolumn{2}{|c|}{ ASSISTANCE } & \multicolumn{2}{|c|}{ KFAIRPOOR } & \multicolumn{2}{|c|}{ KMFAIRPOOR } \\
\hline & Coeff. & St. Err. & Coeff. & St. Err. & Coeff. & St. Err. & Coeff. & St. Err. \\
\hline & \multicolumn{8}{|c|}{ Probit for Employed = 1} \\
\hline Child Health Measure & 0.085 & 2.864 & $-2.466^{* *}$ & 0.487 & -0.565 & 0.819 & -0.468 & 1.389 \\
\hline KID0-5 & -- & -- & -- & -- & -- & -- & -- & -- \\
\hline KID6-11 & 0.042 & 0.075 & 0.038 & 0.074 & 0.036 & 0.075 & 0.033 & 0.075 \\
\hline KID12-15 & $0.270 * *$ & 0.126 & $0.298 * *$ & 0.118 & $0.273 * *$ & 0.119 & $0.271^{* *}$ & 0.120 \\
\hline FAMSIZE & $-0.143^{* *}$ & 0.028 & $-0.146^{* *}$ & 0.024 & $-0.144 * *$ & 0.025 & $-0.146^{* *}$ & 0.024 \\
\hline AGE & 0.048 & 0.069 & 0.049 & 0.046 & 0.048 & 0.046 & 0.052 & 0.046 \\
\hline AGE2 & -0.001 & 0.001 & -0.001 & 0.001 & -0.001 & 0.001 & -0.001 & 0.001 \\
\hline EDUC & $0.057 * *$ & 0.026 & $0.056 * *$ & 0.011 & $0.051^{* *}$ & 0.013 & $0.054 * *$ & 0.012 \\
\hline NOREAST & -0.027 & 0.109 & -0.022 & 0.107 & -0.023 & 0.108 & -0.026 & 0.108 \\
\hline MIDWEST & 0.154 & 0.155 & 0.185 & 0.116 & 0.195 & 0.126 & 0.177 & 0.128 \\
\hline SOUTH & $0.146^{*}$ & 0.080 & $0.154^{* *}$ & 0.078 & $0.161^{* *}$ & 0.081 & $0.154^{*}$ & 0.082 \\
\hline MSA & 0.013 & 0.086 & 0.013 & 0.079 & 0.008 & 0.080 & 0.015 & 0.080 \\
\hline UNEMP & 0.006 & 0.064 & 0.028 & 0.056 & 0.024 & 0.060 & 0.014 & 0.059 \\
\hline BLACK & 0.261 & 0.169 & $0.267^{* *}$ & 0.099 & $0.261^{* *}$ & 0.100 & $0.269 * *$ & 0.100 \\
\hline HISPANIC & $-0.197 * *$ & 0.087 & $-0.193^{* *}$ & 0.075 & $-0.186^{* *}$ & 0.077 & $-0.187 * *$ & 0.080 \\
\hline MARRIED & -0.047 & 0.162 & -0.048 & 0.089 & -0.066 & 0.091 & -0.058 & 0.092 \\
\hline DIVSEP & $0.285^{*}$ & 0.149 & $0.304^{* *}$ & 0.147 & $0.308 * *$ & 0.150 & $0.291^{*}$ & 0.149 \\
\hline GOOD & -0.032 & 0.070 & -0.027 & 0.069 & -0.037 & 0.069 & -0.041 & 0.070 \\
\hline FAIR & -0.177 & 0.114 & -0.175 & 0.112 & -0.171 & 0.115 & $-0.191^{*}$ & 0.113 \\
\hline POOR & -0.183 & 0.257 & -0.185 & 0.257 & -0.161 & 0.258 & -0.189 & 0.258 \\
\hline \multirow[t]{2}{*}{ INTERCEPT } & -0.547 & 0.741 & -0.659 & 0.731 & -0.524 & 0.736 & -0.594 & 0.749 \\
\hline & \multicolumn{8}{|c|}{ Probit for Child Health Measure $=1$} \\
\hline$\overline{\mathrm{APPDIFF}}$ & -0.079 & 0.096 & 0.201 & 0.219 & -0.160 & 0.134 & -0.038 & 0.207 \\
\hline PHONE & 0.141 & 0.089 & $-0.624^{*}$ & 0.343 & 0.074 & 0.120 & 0.253 & 0.184 \\
\hline OBTAIN & 0.125 & 0.094 & 0.252 & 0.204 & $0.248 * *$ & 0.118 & 0.189 & 0.183 \\
\hline AGE & 0.060 & 0.058 & -0.022 & 0.120 & -0.024 & 0.063 & 0.090 & 0.107 \\
\hline AGE2 & -0.001 & 0.001 & 0.001 & 0.002 & 0.000 & 0.001 & -0.001 & 0.002 \\
\hline EDUC & $-0.035^{* *}$ & 0.012 & 0.046 & 0.035 & $-0.048 * *$ & 0.015 & $-0.044^{* *}$ & 0.022 \\
\hline NOREAST & -0.018 & 0.122 & -0.283 & 0.431 & 0.020 & 0.177 & -0.280 & 0.422 \\
\hline MIDWEST & 0.100 & 0.130 & $0.814^{* *}$ & 0.377 & $0.592^{* *}$ & 0.176 & $1.111^{* * *}$ & 0.314 \\
\hline SOUTH & -0.017 & 0.090 & 0.220 & 0.220 & $0.203^{*}$ & 0.117 & $0.435^{* *}$ & 0.203 \\
\hline MSA & -0.038 & 0.090 & 0.089 & 0.226 & -0.095 & 0.114 & 0.212 & 0.228 \\
\hline UNEMP & 0.041 & 0.067 & $0.506^{* * *}$ & 0.175 & $0.266^{* *}$ & 0.084 & $0.440 * *$ & 0.146 \\
\hline BLACK & 0.133 & 0.108 & 0.181 & 0.245 & -0.001 & 0.138 & 0.309 & 0.228 \\
\hline HISPANIC & -0.040 & 0.085 & -0.054 & 0.222 & 0.132 & 0.111 & $0.456^{* *}$ & 0.183 \\
\hline MARRIED & -0.156 & 0.108 & 0.304 & 0.310 & -0.192 & 0.123 & -0.293 & 0.206 \\
\hline DIVSEP & -0.038 & 0.161 & 0.516 & 0.370 & 0.224 & 0.178 & 0.202 & 0.272 \\
\hline INTERCEPT & $-1.675^{* *}$ & 0.862 & $-5.963 * *$ & 2.141 & $-1.955^{*}$ & 1.016 & $-6.401^{* *}$ & 1.808 \\
\hline RHO & -0.128 & 1.624 & 0.894 & 0.163 & 0.244 & 0.400 & 0.224 & 0.604 \\
\hline LR Test & \multicolumn{2}{|c|}{0.01} & \multicolumn{2}{|c|}{1.74} & \multicolumn{2}{|c|}{0.34} & \multicolumn{2}{|c|}{0.14} \\
\hline
\end{tabular}

* significant at 10 percent level $\quad * *$ significant at 5 percent level 
It is important to note that CNR's data set consists of couples who have a child between ages 0 and 2. For purposes of comparison, Table 4 presents estimates for a subsample of mothers who have at least one child between ages 0 and 2 . The bottom row reports a likelihood ratio test for the presence of correlation between the probit error terms. ${ }^{7}$ In contrast to the bottom row of Table 3, the null hypothesis of no correlation is not rejected for any of the four measures of child health, which, similar to CNR, suggests that child health is exogenous with respect to maternal work behavior. Also similar to CNR, and the results of Table 3, none of the measures of child health appears to affect maternal employment, with the exception of ASSISTANCE, which reduces the probability that a mother is employed. Although the difference between the two samples might be due, in part, to differences in sample size, the results appear to suggest that unobserved heterogeneity is an important consideration for mothers of older children.

Another notable difference between CNR and this study concerns the definitions of child health. They consider a child to be in poor health if at least one of the following conditions is true: (1) the child weighed less than 4 pounds at birth; (2) the child is disabled at the follow-up interview; or (3) the child is neither walking nor crawling at the follow-up interview, which occurs 12 to 18 months after birth. Consequently, their definition of child health represents health problems that are likely present from birth. On the other hand, the measures used in this paper are more likely to be acquired as a child ages. Consequently, it is not surprising that when the sample is restricted to mothers with children between ages 0 and 2 , the health variables are predetermined - these children are likely born with health complications. But when the sample includes mothers of older children, some health problems are likely to have developed as a result of socioeconomic circumstances and environments. This hypothesis is supported by the finding in Table 3 that child health problems appear to be positively associated with maternal age. Thus, child health variables for older children are potentially more prone to bias caused by unobserved heterogeneity.

\section{RESULTS OF ESTIMATION}

Because the child health variables are correlated with one another, the employment and hours worked equations are estimated separately for the four measures to avoid multicolinearity problems, similar to the presentation in Tables 3 and 4.

\section{Results Under Assumption that Child Health is Predetermined}

Table 5 presents results for employment and hours worked under the assumption that child health is predetermined. This represents the general manner in which many previous studies have approached this issue. It is used here for purposes of comparison with instrumental variables estimates to be discussed in next subsection. The relevant explanatory variable is LESSHEALTHY, which equals 1 if the mother has any child who is less healthy than other children of similar age. The coefficient of interest, shown in the first row, is negative and significant, which indicates that the presence of an unhealthy child reduces the likelihood of a mother working as well as her number of hours. This result is consistent with the majority of previous studies 
of maternal employment. Other variables are also consistent with previous studies [e.g., Norberg, 1998; Powers, 2003; Corman, Noonan, Reichman, 2005]. The presence of children, especially young children, reduces labor market activity. Employment and hours increase with education and age, but the positive association with age decreases over time, as indicated by the quadratic term. Blacks tend to work more, and Hispanics tend to work less than their nonblack and nonHispanic counterparts. Individuals in good, fair, or poor health work less compared to people in very good or excellent health. Married mothers are less likely to be employed, but mothers separated from their husbands are more likely to be employed and work more hours. In order to account for regional macroeconomic conditions that might affect employment prospects, a measure of the regional unemployment rate at the time of each observation is included in the set of covariates. ${ }^{8}$ Not surprisingly, a higher unemployment rate reduces the likelihood of employment as well as hours worked.

\section{TABLE 5}

\section{The Impact of Child Health on Mothers' \\ Labor Supply Under the Assumption That Child Health is Predetermined}

\begin{tabular}{lcccc}
\hline \multirow{2}{*}{ Variable } & \multicolumn{2}{c}{$\begin{array}{c}\text { EMPLOYED (Probit) } \\
\text { Coeff. }\end{array}$} & St. Err. & HOURS (Tobit) \\
LESSHEALTHY & $-0.045^{* *}$ & 0.012 & $-3.364^{* * *}$ & St. Err. \\
KID0-5 & $-0.103^{* *}$ & 0.012 & $-6.826^{* *}$ & 0.788 \\
KID6-11 & 0.000 & 0.011 & -0.724 & 0.823 \\
KID12-15 & $0.033^{* *}$ & 0.012 & $1.945^{* *}$ & 0.712 \\
FAMSIZE & $-0.032^{* *}$ & 0.004 & $-2.428^{* *}$ & 0.815 \\
AGE & $0.021^{* *}$ & 0.005 & $2.500^{* *}$ & 0.257 \\
AGE2 & $0.000^{* *}$ & 0.000 & $-0.034^{* *}$ & 0.318 \\
EDUC & $0.021^{* *}$ & 0.002 & $1.345^{* *}$ & 0.004 \\
NOREAST & -0.022 & 0.015 & -1.523 & 0.113 \\
MIDWEST & $0.038^{* *}$ & 0.017 & $1.811^{*}$ & 1.029 \\
SOUTH & $0.022^{*}$ & 0.012 & $2.470^{* *}$ & 1.133 \\
MSA & 0.003 & 0.011 & -0.087 & 0.793 \\
UNEMP & $-0.015^{*}$ & 0.008 & $-1.006^{*}$ & 0.755 \\
BLACK & $0.046^{* *}$ & 0.013 & $3.929^{* *}$ & 0.530 \\
HISPANIC & $-0.046^{* *}$ & 0.012 & $-1.694^{* *}$ & 0.880 \\
MARRIED & $-0.027^{*}$ & 0.015 & 0.257 & 0.785 \\
SEP & $0.048^{* *}$ & 0.017 & $5.312^{* *}$ & 1.001 \\
GOOD & $-0.018^{*}$ & 0.010 & $-1.905^{* *}$ & 1.156 \\
FAIR & $-0.121^{* *}$ & 0.016 & $-7.860^{* *}$ & 0.687 \\
POOR & $-0.313^{* *}$ & 0.030 & $-20.245^{* *}$ & 1.066 \\
INTERCEPT & $0.426^{* *}$ & 0.092 & $-25.176^{* *}$ & 2.196 \\
\hline
\end{tabular}

* $\quad$ significant at 10 percent level

** significant at 5 percent level

Estimates of the model shown in Table 5 were repeated for other measures of child health (FAIRPOOR, MFAIRPOOR, ASSISTANCE). Coefficients of control variables are similar regardless of which child health variable is included in the model and are also similar compared to models that control for unobserved heterogeneity (to be discussed below). Therefore, for the sake of brevity, the remainder of the paper presents only estimates of the child health coefficient. Full results are available upon request. 
The first column of Table 6 shows estimated coefficients of the child health variables for the four alternative health indicators when child health is treated as predetermined. The entry in the first row and first column, denoted Model 1, reproduces estimates from Table 5. Because the Tobit model is nonlinear in its conditional mean, marginal effects are calculated for each individual, and the average across individuals is reported in brackets. Marginal effects for the LPM models are identical to the estimated coefficients. Three of the four measures of child health are associated with reductions in labor market participation. A mother with a child who is less healthy than other children is approximately 5 percentage points less likely to be employed; a mother with a child who needs mechanical or personal assistance is 7 percentage points less likely to be employed; and the probability of employment decreases by approximately 5 percentage points if a mother has a child in fair or poor mental health. Tobit results show that the presence of a child who requires mechanical or personal assistance does not appear to affect a mother's number of hours worked per week, but having a child who is less healthy than other children and having a child in fair or poor mental health are associated with reductions of 2.49 and 4.03 hours, respectively.

TABLE 6

The Impact of Child Health on Maternal Labor Supply: Estimates from Alternative Models

\begin{tabular}{lcccccccc}
\hline & $\begin{array}{c}\text { Model 1 } \\
\text { Child Health } \\
\text { Predetermined }\end{array}$ & \multicolumn{2}{c}{$\begin{array}{c}\text { Model 2 } \\
\text { Instrumental } \\
\text { Variables }\end{array}$} & \multicolumn{2}{c}{$\begin{array}{c}\text { Model 3 } \\
\text { Married } \\
\text { Only }\end{array}$} & \multicolumn{2}{c}{$\begin{array}{c}\text { Model 4 } \\
\text { Nonmarried } \\
\text { Only }\end{array}$} \\
\hline Health Condition & EMPLOYED HOURS & EMPLOYED HOURS & EMPLOYED HOURS EMPLOYED HOURS \\
\hline Less & $-0.045^{* * *}$ & $-3.364^{* * *}$ & 0.173 & 9.246 & 0.105 & 29.887 & 0.006 & -2.068 \\
Healthy & $(-0.012)$ & $(-0.788)$ & $(0.244)$ & $(17.257)$ & $(0.382)$ & $(30.031)$ & $(0.246)$ & $(17.078)$ \\
& & {$[-2.49]$} & & {$[6.83]$} & & {$[21.88]$} & & {$[-1.64]$} \\
Needs & $-0.071^{* * *}$ & -1.679 & 2.619 & 17.257 & 1.517 & -19.396 & -0.590 & -27.142 \\
Assistance & $(-0.037)$ & $(2.511)$ & $(1.785)$ & $(80.224)$ & $(1.203)$ & $(57.620)$ & $(2.283)$ & $(53.998)$ \\
& & {$[-1.24]$} & & {$[12.95]$} & & {$[-14.19]$} & & {$[-21.53]$} \\
Fair or Poor & -0.019 & -1.215 & 0.887 & -19.405 & 1.156 & $40.134^{*}$ & 0.248 & -11.583 \\
Physical Health & $(0.019)$ & $(1.315)$ & $(0.655)$ & $(22.242)$ & $(1.097)$ & $(22.583)$ & $(0.584)$ & $(38.078)$ \\
& & {$[-0.90]$} & & {$[-14.34]$} & & {$[29.37]$} & & {$[-9.19]$} \\
Fair or Poor & $-0.047^{*}$ & $-5.454^{* *}$ & 0.645 & -9.188 & 0.484 & 35.324 & 0.198 & -6.539 \\
Mental Health & $(0.025)$ & $(1.709)$ & $(0.607)$ & $(23.432)$ & $(0.943)$ & $(25.826)$ & $(0.574)$ & $(30.438)$ \\
& & {$[-4.03]$} & & $-6.79]$ & & {$[25.85]$} & & {$[-5.19]$}
\end{tabular}

Sample size 8773 8773 6187 2586

* significant at 10 percent level

** significant at 5 percent level

Note: Standard errors in parentheses, and marginal effects in brackets.

The results in the first column of Table 6 are qualitatively and quantitatively similar to other studies of child health and maternal work, including Powers [2003] and Corman, Noonan, and Reichman [2005]. Although the reduction in hours might appear quantitatively small, policy implications are potentially important if the reduction shifts mothers from full time work to part time work. Most employers offer health benefits only to full time employees. Consequently, if having an unhealthy child reduces maternal hours of work, family health might be further hindered by a potential loss 
of employer-provided coverage.$^{9}$ However, if unobserved family heterogeneity affects child health and maternal work activity, then these results cannot be interpreted as causal effects. The next section attempts to control for unobserved heterogeneity.

\section{Results Correcting for Unobserved Heterogeneity}

The second column of Table 6 presents coefficients of child health that control for the presence of unobserved heterogeneity. The EMPLOYED models are estimated by linear IV, and the HOURS models use a Tobit specification in which child health is replaced by fitted values from a first stage probit. Tobit standard errors are estimated by bootstrap to account for the fact that the child health variable is an estimate.

In contrast to results under the assumption of predetermined child health, and in contrast to previous research, none of the measures of child health appears to affect either the likelihood of employment or number of hours worked. Estimated coefficients for these models are larger in magnitude than their corresponding values from the first column, and in several cases the signs are reversed, but they are estimated with less precision. Estimation under the assumption of predetermined child health for both measures of employment revealed that having an unhealthy child impedes maternal work, but the effects become insignificant when unobserved heterogeneity is taken into account.

The contrast in results between Models 1 and 2 implies that mothers with healthy children differ from mothers with unhealthy children in ways that are not observed in household surveys. And it is these differences that affect maternal work patterns-not necessarily the presence per se of healthy or unhealthy children. Because these results are contrary to past research, the source of unobserved heterogeneity that appears to be affecting the results is a principal concern. One explanation is that mothers of unhealthy children might themselves be unhealthier than mothers of healthy children. As the table below shows, mothers of unhealthy children are less likely to report their health status as "excellent" or "very good" and are more likely to report their health as "fair" or "poor".

Child's Health

\begin{tabular}{lcc}
\hline Mothers' Self-reported health & LESSHEALTHY=0 & LESSHEALTHY=1 \\
\hline Very good or excellent & 0.63 & 0.50 \\
Good & 0.26 & 0.32 \\
Fair & 0.09 & 0.14 \\
Poor & 0.02 & 0.04 \\
\hline
\end{tabular}

Results in the first column of Table 6 that treat child health as predetermined include self-reported health as control variables. Many researchers argue that categorical measures of self-reported health are poor proxies for actual health [Lindeboom and van Doorslaer, 2004]. Consequently, models of maternal work that do not account for unobserved heterogeneity might neglect to control for unobserved characteristics of maternal health. Results in the second column of Table 6 explicitly control for the presence of unobserved heterogeneity, and thus the link between child health and maternal work is weakened. These results suggest that mothers of unhealthy children 
possess unmeasured health traits that impede labor force participation-it is not necessarily the presence per se of unhealthy children that explains their reduced participation.

\section{Robustness Checks}

While some previous studies have focused on the effects of young children or infants, this paper considers children of various ages. Expanding on this idea, the models are estimated after refining the child health measures into age categories zero to 5 years, 6 to 11 years, and 12 to 15 years. For this experiment, the child is defined as unhealthy if any of the four health problems considered in the previous models are present. Results reported in Table 7 suggest that after controlling for unobserved heterogeneity, mothers' employment behaviors do not vary with respect to ages of unhealthy children. Similar to results reported in Table 6, child health does not appear to be an important determinant of maternal employment activity.

\section{TABLE 7}

Comparison of the Effect of Child Health by Age Group

\begin{tabular}{lccccc}
\hline \multicolumn{3}{c}{ EMPLOYED (IV) } & \multicolumn{3}{c}{ HOURS (Tobit) } \\
\hline Model & Coeff. & St. Err. & Coeff. & St. Err. & Marg. Eff. \\
\hline Sick kid 0 to 5 & 50.529 & 0.818 & 2.183 & 24.314 & {$[1.62]$} \\
Sick kid 6 to 11 & 0.435 & 0.353 & 8.552 & 13.296 & {$[6.32]$} \\
Sick kid 12 to 15 & 0.393 & 0.376 & -9.193 & 11.362 & {$[-6.79]$} \\
\hline
\end{tabular}

* significant at 10 percent level

** significant at 5 percent level

It is possible that maternal work responds differently to child health depending on whether the mother is married. For example, a married mother with an unhealthy child might be under less pressure to work than a single mother, especially if her husband is the principal breadwinner in the family. In the sample, 71 percent of mothers are married and the remaining 29 percent are nonmarried. All models were re-estimated for both subsamples. Results from the partitioned samples, shown in the third and fourth columns of Table 6, are similar to those of the full sample. After controlling for unobserved heterogeneity, child health does not appear to affect the likelihood of employment for either married or nonmarried mothers. Further, child health does not appear to impact the number of hours per week, with the exception that the presence of a child in fair or poor health appears to increase the number of hours worked. With respect to all models, most of the results from the subsamples are estimated with less precision than those reported in the second column of Table 6 , which is likely due to reduced sizes of the subsamples.

Overall, estimation based on the partitioned sample leads to two conclusions. First, in support of results from the full sample, maternal work patterns do not appear to be affected by the presence of unhealthy children, after controlling for unobserved heterogeneity. Second, maternal employment responses to unhealthy children do not differ between unmarried and married mothers. An interesting question for future research is whether changes in marital status cause changes in maternal responses to child health. 


\section{NLSY Comparison}

Although the three access to care variables are supported by instrument validity tests, the fact that they are self-reported raises questions about their appropriateness. As a robustness check, a sample of mothers is drawn from another national survey, the 1979 cohort of the National Longitudinal Survey of Youth (NLSY). The 1979 NLSY originally consisted of 12,686 individuals who were between ages 14 and 21 in 1979 . This cohort has been interviewed annually or biannually since 1979. In 2002, 8,033 individuals remained in the survey. Although the primary focus of the survey is on labor market behavior, in 1986 the National Institute of Child Health and Human Development sponsored a biannual supplemental survey of children born to women of the 1979 NLSY cohort available for the years 1986, 1988, 1990, and 1992, which means these individuals were surveyed before welfare reforms took place in the mid 1990s. This supplemental survey includes measures of child health.

A panel of the years 1986, 1988, 1990, and 1992 was extracted, including information on maternal work behavior and child health. Only mothers and children with four years of information are retained, leaving 2,237 mothers for a total of 8,948 mother-year observations. In addition to the smaller sample size of mothers, the NLSY is inferior to MEPS in this application for several reasons. First, since NLSY respondents were ages 14 to 21 in 1979, the oldest mothers were in their mid 30s by 1992, and this robustness exercise consequently focuses on younger women. Second, few children in NLSY report health problems, so effects are harder to estimate with precision. Due to small sample averages of child health variables, and in an attempt to mimic results above, the variable SICKKID takes a value of 1 if any of the following are true: (1) the child has a health condition that limits school work; (2) the child has a health condition that requires medication; (3) the child has a health condition that requires the use of assistive equipment; or (4) the child is physically crippled. SICKKID takes a value of 0 if none of these four health problems is present. Approximately 7 percent of mothers have a child with one of these health problems. ${ }^{10}$

Despite weaknesses of NLSY compared to MEPS, the panel structure offers the opportunity to control for unobserved heterogeneity even without suitable instruments. The use of fixed effects controls for unobserved family-specific heterogeneity that is constant across the four years of data. Thus, unobserved factors affecting child health and maternal employment behavior that are not time dependent can be accounted for through the panel structure. The models also control for mother's age and education, child age, presence of a father in the house, and year fixed effects that control for unobserved factors common to all families that change over time.

In the following table, the first column of results under the heading "Pooled Regression" pools the data and ignores the panel structure. The dependent variable is a dichotomous variable equaling 1 if the mother is employed. ${ }^{11}$ This result is comparable to results in Table 6 that ignore unobserved heterogeneity.

Dependent Variable $=$ EMPLOYED

\begin{tabular}{lcccc}
\hline & \multicolumn{2}{c}{ Pooled Regression } & \multicolumn{2}{c}{ Individual Fixed Effects } \\
\hline & Coeff. & St. Err. & Coeff. & St. Err. \\
\hline SICKKID & $-0.042^{* *}$ & 0.020 & -0.004 & 0.022 \\
\hline
\end{tabular}


When a mother has an unhealthy child, she is approximately 4 percentage points less likely to be employed. On the other hand, the coefficient of child health is insignificant when the panel structure is exploited through fixed effects. This finding is consistent with IV results from MEPS reported in Table 6, although the latter results are larger in magnitude. When unobserved heterogeneity is ignored, child health problems have a negative and significant affect on maternal employment. On the other hand, fixed effects estimates, which accommodate time invariant unobserved factors that simultaneously affect child health and maternal employment, suggest that child health problems are not a significant obstacle to maternal employment. The implication is that the link between child health and maternal work is primarily due to unobserved family traits as opposed to a direct causal impact.

\section{Discussion}

Understanding the link between child health and maternal work is important for several reasons. First, research shows that poorer families are more likely to have an unhealthy child [Brooks-Gunn and Duncan, 1997]. Powers [2003] argues that if the presence of an unhealthy child impedes maternal work, this could exacerbate income inequality. Powers also claims that if loss of parental earnings is a primary justification of generous child disability subsidies, then the link between child health and maternal work behavior must be quantified. The relationship between mothers' work and the health of their children is also important in assessing the impact of Personal Responsibility and Work Opportunity Reconciliation Act of 1996, which increased incentives to leave welfare and enter the labor force. If child health problems present obstacles for mothers seeking employment, then perhaps work requirements of the welfare reform act should be relaxed for mothers of unhealthy children. In light of the reforms, it is important to determine whether child health affects mothers' employment activities.

In the presence of an unhealthy child, it is not clear a priori whether mothers might increase their work behavior to obtain extra income or decrease work to provide child care. It is unlikely, however, that the evidence presented above that child health does not affect maternal work is due to these two effects canceling each other out. MEPS data contain an indicator of whether each person missed any work because of someone else's health condition. Approximately 31 percent of mothers report missing work because of another's health. The following table shows how this value varies with respect to child health.

\begin{tabular}{lcc} 
Child Health Measure & Health Measure $=\mathbf{1}$ & Health Measure $=\mathbf{0}$ \\
\hline & Proportion of mothers missing work for someone else's health \\
\hline LESSHEALTHY & 0.315 & 0.313 \\
ASSISTANCE & 0.374 & 0.313 \\
FAIRPOOR & 0.391 & 0.309 \\
MFAIRPOOR & 0.339 & 0.313 \\
\hline
\end{tabular}

Although a slightly higher percentage of mothers miss work when they have a child who needs assistance or is in fair or poor health, none of the differences in the 
proportion of mothers missing work is statistically significant using a two population test. This further supports the main hypothesis that child health is not a substantial obstacle to maternal work.

With the exceptions of Norberg [1998] and Corman, Noonan, and Reichman [2005], previous studies have ignored the problem of unobserved heterogeneity. The latter analysis finds that child health is predetermined in model of maternal labor supply. As discussed above, however, by focusing on mothers of young children and using a measure of child health that represents problems that are likely present at birth, their results are less subject to bias caused by unobserved heterogeneity. The results of this paper suggest that measures of child health which potentially develop after birth might be affected by unobserved confounding factors that also influence maternal work activity. These results highlight the need for further research, because, similar to this paper, most existing studies consider mothers of older children and use measures of child health that cannot be justified as predetermined.

The key finding of this paper is that the link between some measures of child health and maternal work behavior appears to be the result of unobserved differences between mothers who have unhealthy children and those who have healthy children. This unobserved heterogeneity is the principal determinant of differences in work patterns between the two groups. One possibility is that mothers of unhealthy children tend to have unmeasured health problems of their own, and these health problems potentially impede work activity. This questions the conventional view that child health problems present direct obstacles to employment. A priority for future research is to further delineate the unobserved differences between mothers with unhealthy children and mothers with healthy children and determine how they affect employment.

\section{Concluding Remarks}

This paper offers several advances on the subject of child health and maternal employment. It addresses the issue of unmeasured factors that influence both child health and maternal employment by using unique variables that describe family access to care. Moreover, several indicators of child health are utilized, including indicators of the age of the unhealthy child. Most previous research on the link between child health and maternal work suggests that children in poor health impede mothers' work. In this paper, results estimated under the assumption of predetermined child health come to the same conclusion. However, using access to care variables as instruments, the negative effect of child health on mothers' work becomes insignificant. The results suggest that previous studies have presented a reduced form result in which unobserved heterogeneity is a component of the link between child health and maternal work. Results also suggest that married mothers and nonmarried mothers do not substantially differ in their responses to unhealthy children.

A possible avenue for future research is to determine whether the main results differ using data from before the 1996 welfare reforms. Perhaps the negative link uncovered in some earlier studies is present even after controlling for endogeneity, because work requirements were not as stringent prior to welfare reform. Such a 


\section{study requires pre-1996 data that includes not only measurements of child health, but also measures of access to care.}

\section{NOTES}

The opinions expressed in this paper are those of the author and do not necessarily represent those of the FTC or its individual Commissioners.I wish to thank Hope Corman, Michael Zimmer, and four anonymous referees for helpful comments.

1. The reader is encouraged to consult Heckman [1974] and Salkever [1982] for technical details of the theoretical model.

2. Appendix 1 shows that in a model where child health is treated as predetermined, when probit coefficients are converted to represent changes in probability of the outcome variable, probit results are virtually identical to LPM results.

3. After the initial Tobit parameters are estimated, a random sample of the same size as the parent population is drawn, with replacement, from the parent sample. The two step estimation procedure is then repeated using the randomly drawn sample. This procedure is repeated 200 times, and the asymptotic covariance matrix is given by

Asy. Var.

$$
[\theta]=\frac{1}{200} \sum_{b=1}^{200}[\theta(b)-\theta][\theta(b)-\theta]^{\prime} .
$$

This matrix then becomes the basis for inferences concerning the population parameters, with particular attention to the partial effect of child health on the mother's labor force behavior.

4. FAIR and POOR are combined for child health measures, because fewer than 1 percent of children are in poor physical or mental health. Thus, the variables FAIRPOOR and MFAIRPOOR are interpreted as general indicators of children who are in the bottom end of the distribution of self-reported health.

5. It is not possible to calculate the Hansen test for the Tobit model. Therefore, for purposes of calculating the test, HOURS is estimated using linear instrumental variables analysis. For the efficient generalized method of moments estimator (GMM), the statistic is calculated as the minimized value of the GMM criterion function and is consistent under the presence of heteroskedasticity. The GMM estimator minimizes the objective function $\mathrm{Ng}^{\prime} \mathrm{Hg}$ where $\mathrm{N}$ is the sample size, $\mathrm{g}$ consists of the moment conditions of instruments exogeneity, and $\mathrm{H}$ is the optimal weighting matrix.

6. Some variables such as maternal health are excluded in the child health equation due to potential correlation with unobserved components of child health.

7. The test statistic follows a Chi-square distribution with 1 degree of freedom.

8. Regional unemployment rates are collected by the U.S. Census Bureau.

9. If an unhealthy child has access to disability compensation, the extra income might reduce the mother's labor force attachment. Separate models were estimated in which the mother's labor supply equation included a dummy variable indicating whether her unhealthy child receives disability income. Although this variable was negative and highly significant, it is not included in the baseline models due to correlation with the child health variable of interest. A child is eligible for compensation if he or she is disabled, so including this variable in the mother's labor equation is potentially redundant with the child health variable of interest. Therefore, to avoid possible problems of multicolinearity, disability compensation is not included as an explanatory variable.

10. This measure of child health is different from those used in earlier sections. Direct comparison of these results with those from MEPS should be done with caution.

11. It is not possible to consistently estimate a fixed effects tobit model for the HOURS equation in this application. Greene [2004] shows that in panels shorter than 5 years, standard errors and marginal effects are subject to large bias due to the problem of incidental parameters. The more widely used random effects tobit model requires that the unobserved person-specific component be uncorrelated with regressors, which is not satisfied in this application as unobserved access to care characteristics are clearly correlated with child health. 


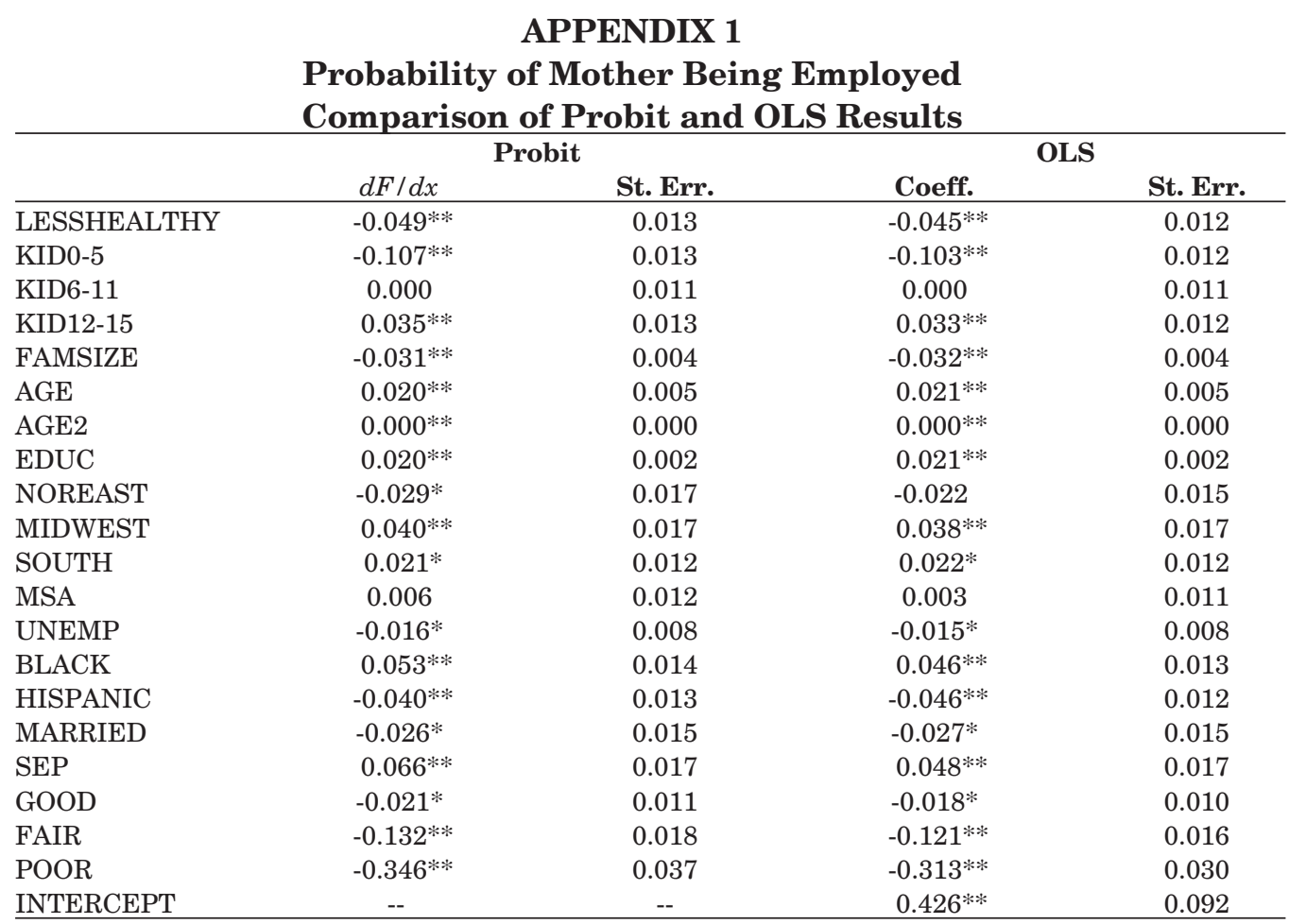

* $\quad$ significant at 10 percent level

** $\quad$ significant at 5 percent level

Comparison of partial effects from probit estimation with OLS coefficients for the linear probability model (LPM) reveals strong similarities. Consequently, LPM results are reported in Tables 6-9.

\section{REFERENCES}

Blank, R. The Effect of Medical Need and Medicaid on AFDC Participation. The Journal of Human Resources, Winter 1989, 54-87.

Breslau, N., Salkever, D. and Staruch, K. Women's Labor Force Activity and Responsibilities for Disabled Dependents: A Study of Families with Disabled Children. Journal of Health and Social Behavior, June 1982, 169-183.

Brooks-Gunn, J. and Duncan, G. The Effects of Poverty on Children. The Future of Children: Children and Poverty, Summer/Fall 1997, 55-71.

Corman, H., Noonan, K. and Reichman, N. Mothers' Labor Supply in Fragile Families: The Role of Child Health. Eastern Economic Journal, 31,4, 2005.

Efron, B. Bootstrapping Methods: Another Look at the Jackknife. Annals of Statistics, 1979, 1-26.

Greene, W. Fixed Effects and Bias Due to the Incidental Parameters Problem in the Tobit Model. Econometric Reviews, 23, 2, 2004, 125-47.

Hansen, L. P. Large Sample Properties of Generalized Method of Moments Estimators. Econometrica, July 1982, 1029-1054.

Heckman, J. Effects of Child-Care Programs on Women's Work Effort. Journal of Political Economy, March/April 1974, S136-S163.

Kimmel, J. Reducing the Welfare Dependence of Unmarried Women: Health-Related Employment Barriers and Policy Responses. Eastern Economic Journal, Spring 1997, 151-163.

Lindeboom, M. and van Doorslaer, E. Cut-point Shift and Index Shift in Self-reported Health. Journal of Health Economics, November 2004, 1083-1099. 
Lukemeyer, A., Meyers, M. K. and Smeeding, T. Expensive Children in Poor Families: Out-of-Pocket Expenditures for the Care of Disabled and Chronically Ill Children in Welfare Families. Journal of Marriage and the Family, May 2000, 399-415.

Nelson, C. and Startz, R. Some Further Results on the Exact Small Sample Properties of the Instrumental Variables Estimator. Econometrica, July 1990, 967-976.

Norberg, K. The Effects of Daycare Reconsidered. NBER working paper, October 1998.

Porterfield, S. Work Choices of Mothers in Families with Children with Disabilities. Journal of Marriage and Family, November 2002, 972-981.

Powers, E. Children's Health and Maternal Work Activity: Estimates under Alternative Disability Definitions. The Journal of Human Resources, Summer 2003, 522-556.

Roberts, A. The Labor Market Consequences of Family Illness. The Journal of Mental Health Policy and Economics, December 1999, 183-195.

Salkever, D. Children's Health Problems and Maternal Work Status. The Journal of Human Resources, Winter 1982, 94-109.

Salkever, D. Child Health and Other Determinants of Single Mothers' Labor Supply and Earnings, in Research in Human Capital and Development 6, edited by I. Sivageldin, A. Sorkin, and R. Frank. London: JAI Press, 1990, 147-181.

Wolfe, B. and Hill, S. The Effect of Health on the Work Effort of Single Mothers. The Journal of Human Resources, Winter 1995, 41-62. 